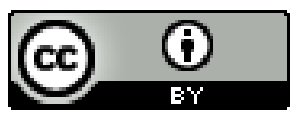

\title{
A IMPLEMENTAÇÃO DAS DIRETRIZES CURRICULARES NACIONAIS PARA A EDUCAÇÃO DAS RELAÇÕES ÉTNICO- RACIAIS: SUBVERSÃO À LÓGICA DA COLONIALIDADE NO CURRÍCULO ESCOLAR
}

\author{
Eugenia Portela de Siqueira Marques ${ }^{1}$ \\ Valeria Aparecida Mendonça de Oliveira Calderoni ${ }^{2}$
}

Resumo: As Diretrizes Curriculares Nacionais para a Educação das Relações Étnico-raciais (DCNERER) promoveram um deslocamento epistêmico no sentido de subverter a lógica hegemônica ocidental de matriz monocultural dos currículos escolares. O estudo analisa a implementação das leis $n^{\circ}$. 10.639/2003 e $n^{\circ}$. 11.645/2008 no estado Mato Grosso do Sul, a partir de uma pesquisa finanaciada pela Fundação de Apoio ao Desenvolvimento do Ensino, Ciência e Tecnologia do Estado de Mato Grosso do Sul, realizada em escolas públicas no período de 2014 a 2016. Adotou-se como procedimento teórico metodológico a aplicação de questionários on line, realização de entrevistas. Conclui-se que ocorreram avanços importantes, todavia ainda é necessário avaliar em que medida o currículo escolar e a formação inicial e continuada de professores atendem satisfatoriamente as diretrizes.

Palavras-chave: Educação. Relações étnico-raciais. Currículo escolar. Descolonialidade

\section{THE IMPLEMENTATION OF THE NATIONAL CURRICULUM GUIDELINES FOR THE EDUCATION OF ETHNIC-RACIAL RELATIONS: SUBVERSION TO THE LOGIC OF COLONIALITY IN THE SCHOOL CURRICULUM}

Abstract: The National Curriculum Guidelines for the Education of Ethnic-Racial Relations (DCNERER) promoted an epistemic shift in order to subvert the western hegemonic logic of a

\footnotetext{
${ }^{1}$ Doutora em Educação pela UFSCar . Docente na Universidade Federal de Mato Grosso do Sul (UFMS). Líder do Grupo de Estudos e Pesquisas sobre Educação, Relações étnico-raciais e Formação de professores - GEPRAFE. Coordenadora do GT 21 ANPED- Educação e Relações étnico-raciais. E-mail: portelaeugenia@gmail.com

2 Doutora e Mestre em Educação pela Universidade Católica Dom Bosco. Graduada em Educação Artística e em Pedagogia. Professora da Secretaria de Estado de Educação de Mato Grosso do Sul. Membro do Núcleo de Estudos Afro-brasileiro- NEAB/UFGD e do Grupo de Estudos e Pesquisas sobre Educação, Relações étnico-raciais e Formação de professores - GEPRAFE. E-mail: lela_13613@yahoo.com.br
} 
monocultural matrix of school curricula. The study analyzes the implementation of laws no. 10,639 / 2003 and no. 11,645 / 2008 in the state of Mato Grosso do Sul, based on a research funded by the Support Foundation for the Development of Education, Science and Technology of the State of Mato Grosso do Sul, carried out in public schools from 2014 to 2016. It was adopted as a methodological theoretical procedure the application of online questionnaires, conducting interviews. It is concluded that important advances have occurred, however it is still necessary to assess the extent to which the school curriculum and the initial and continuing teacher training satisfactorily meet the guidelines.

Key words: Education. Ethnic-racial relations. School curriculum. Decoloniality.

\section{LA APLICACIÓN DE LAS DIRECTRICES NACIONALES DEL CURRÍCULO PARA LA EDUCACIÓN DE LAS RELACIONES RETO-ÉTNICAS: SUBVERSIÓN A LA LÓGICA DE LA COLONIALIDAD EN EL CURRÍCULO ESCOLAR}

Resumen: Las Directrices Curriculares Nacionales para la Educación de las Relaciones ÉtnicoRaciales (DCNERER) promovieron un cambio epistémico para subvertir la lógica hegemónica occidental de una matriz monocultural de currículos escolares. El estudio analiza la implementación de las leyes no. 10.639 / 2003 y no. 11.645 / 2008 en el estado de Mato Grosso do Sul, basado en una investigación financiada por la Fundación de Apoyo para el Desarrollo de la Educación, la Ciencia y la Tecnología del Estado de Mato Grosso do Sul, realizada en escuelas públicas de 2014 a 2016. Fue adoptada como procedimiento teórico metodológico la aplicación de cuestionarios en línea, realización de entrevistas. Se concluye que se han producido avances importantes, sin embargo, aún es necesario evaluar el grado en que el plan de estudios de la escuela y la formación inicial y continua del maestro satisfacen satisfactoriamente las pautas.

Palabras clave: educación. Relaciones étnico-raciales. Currículum escolar. Decolonialidad.

\section{LA MISE EN GEUVRE DE LIGNES DIRECTRICES NATIONALES POUR UN CURRICULUM D'ÉDUCATION ETHNIQUE ET RACIALE: SUBVERSION À LA LOGIQUE DE LA COLONIALITÉ DANS LE PROGRAMME SCOLAIRE}

Résumé: Las Directrices Curriculares Nacionales para la Educación de las Relaciones ÉtnicoRaciales (DCNERER) promovieron un cambio epistémico para subvertir la lógica hegemónica occidental de una matriz monocultural de currículos escolares. El estudio analiza la implementación de las leyes no. 10.639 / 2003 y no. 11.645 / 2008 en el estado de Mato Grosso do Sul, basado en una investigación financiada por la Fundación de Apoyo para el Desarrollo de la Educación, la Ciencia y la Tecnología del Estado de Mato Grosso do Sul, realizada en escuelas públicas de 2014 a 2016. Fue adoptada como procedimiento teórico metodológico la aplicación de cuestionarios en línea, realización de entrevistas. Se concluye que se han producido avances importantes, sin embargo, aún es necesario evaluar el grado en que el plan de estudios de la escuela y la formación inicial y continua del maestro satisfacen satisfactoriamente las pautas.

Mots-clés: éducation. Relations ethno-raciales. Programme scolaire. Décolonialité

\section{INTRODUÇÃO}


Descolonizar-se, esta é a possibilidade do pensamento.

Walsh (2005, p.22)

Os caminhos investigativos orientados por autores pós-coloniais sobre o currículo escolar no Brasil mostram que suas narrativas legitimaram as epistemologias do colonizador que resultou na subjugação, subalternização e a inferiorização dos saberes $^{3}$ dos povos tradicionais africanos e indígenas. Apesar da nossa Magna Carta de 1988 garantir os "Direitos Culturais", na Seção II, Art. 215, parágrafo 1º que dispõe sobre a cultura, observa-se que na prática ocorreram muitas resistências para que as culturas afro-brasileira e indígena fossem inseridas nas políticas de currículo.

A implementação das Leis $n^{\circ} 10.639 / 2003 ; n^{\circ} 11645 / 2008$ e as Diretrizes Curriculares Nacionais para a Educação das Relações Étnico-raciais e para o Ensino de História e Cultura Afro-brasileira e Africana instigam reflexões sobre o desafio estabelecido para a concretização de uma pedagogia decolonial ${ }^{4}$ que possibilite construir ou ressignificar o espaço que essas culturas ocupam no currículo das escolas brasileiras.

Esse arcabouço jurídico possibilitou analisar criticamente o currículo escolar, numa perspectiva intercultural e decolonial no sentido de tensionar discussões sobre a racialização, a subalternização e a inferiorização que os padrões de poder de matriz colonial europeia impuseram ao inviabilizar diálogos outros ${ }^{5}$ com saberes diferentes.

\footnotetext{
${ }^{3}$ Para fazer referência a saber e conhecimento como sinônimo, entendemos com Mato (2009) que não há hierarquia entre saber e conhecimento, mas sim um processo histórico que desqualificou um determinado conhecimento, e que ainda se faz presente como uma herança colonial, a colonialidade do saber.

${ }^{4}$ Pedagogia decolonial - A decolonialidade representa uma estratégia que vai além da transformação da descolonização, ou seja, supõe também construção e criação. Sua meta é a reconstrução radical do ser, do poder e do saber (FERNANDES, 2010, p.24).Tendo este entendimento, segundo autor, Walsh (2009) vai propor "[...]uma práxis baseada numa insurgência educativa propositiva - portanto, não somente denunciativa - em que o termo insurgir representa a criação e a construção de novas condições sociais, políticas, culturais e de pensamento. Em outros termos, a construção de uma noção e visão pedagógica que se projeta muito além dos processos de ensino e de transmissão de saber, que concebe a pedagogia como política cultural (p.28).

${ }^{5}$ Incorporada nos discursos dos autores pós-coloniais do MC, olhares outros, saberes outros, trata-se de uma resposta, de um "[...] não ao moderno-ocidental-colonial" (MIGNOLO ,2003).
} 
Sob essa ótica, Walsh (2009, p.15) considera que:

A interculturalidade crítica e a decolonialidade, nesse sentido, são projetos, processos e lutas que se entrecruzam conceitualmente e pedagogicamente, alentando forças, iniciativas e perspectivas éticas que fazem questionar, transformar, sacudir, rearticular e construir. Essa força, iniciativa, agência e suas práticas dão base para o que chamo de continuação da pedagogia decolonial.

Nesse sentido, a pedagogia decolonial é um instrumento pedagógico que nos provoca a questionar qual o lugar que os saberes africanos e indígenas ocupam no currículo escolar, considerando que as teorias tradicionais não podem ser vistas de forma ingênua, pois o currículo compreendido como “[...] uma trajetória, relação de poder, documento de identidade" (SILVA, 2002, p.150). Se constitui no aspecto fundamental de análise para se compreender quais as intenções estão presentes na forma de organização escolar, no trabalho pedagógico e a relação com o conhecimento no contexto da educação escolar.

A seleção dos conhecimentos legitimados como universais no currículo escolar foi imposta e legitimadas, e representa o que foi considerado socialmente por um determinado período na história da sociedade. Conforme Silva (2009, p.195):

As narrativas contidas no currículo trazem embutidas noções sobre quais grupos sociais podem representar a si e aos outros e quais grupos sociais podem apenas ser representados ou até mesmo serem totalmente excluídos de qualquer representação. Elas, além disso, representam os diferentes grupos sociais de forma diferente: enquanto as formas de vida e a cultura de alguns grupos são valorizadas e instituídas como cânon, as de outros são desvalorizadas e proscritas. Assim, as narrativas do currículo contam histórias que fixam noções particulares sobre gênero, raça, classe - noções que acabam também nos fixando posições muito particulares ao longo desses eixos.

Subverter à lógica da colonialidade ${ }^{6}$ curricular é desobedecer a estrutura de hierarquização de cultura e saberes, é questionar os arranjos institucionais que

\footnotetext{
${ }^{6} \mathrm{O}$ colonialismo denota uma relação política e econômica, na qual a soberania de um povo está no poder de outro povo ou nação, o que constitui a referida nação em um império. Diferente desta idéia, a colonialidade se refere a um padrão de poder que emergiu como resultado do colonialismo moderno, mas em vez de estar limitado a uma relação formal de poder entre dois povos ou nações, se relaciona à forma
} 
alimentam situações de preconceito e discriminação que produzem representações estereotipadas e desrespeitosas contra os indivíduos que pertencem a uma outra cultura.

A DCNERER (BRASIL, 2004) guia as unidades escolares na busca por uma educação que respeite a alteridade e a cultura do "outro", segundo suas orientações, é necessário que se constituam em espaço democrático de produção e divulgação de saberes, como também a construção de posturas que busquem a equidade. Neste sentido nos orienta:

Combater o racismo, trabalhar pelo fim da desigualdade social e racial, empreender reeducação das relações étnico-raciais não são tarefas exclusivas da escola. As formas de discriminação de qualquer natureza não têm o seu nascedouro na escola, porém o racismo, as desigualdades e discriminações correntes na sociedade perpassam por ali. Para que as instituições de ensino desempenhem a contento o papel de educar, é necessário que se constituam em espaço democrático de produção e divulgação de conhecimentos e de posturas que visam a uma sociedade justa. A escola tem papel preponderante para eliminação das discriminações e para emancipação dos grupos discriminados, ao proporcionar acesso aos conhecimentos científicos, a registros culturais diferenciados, à conquista de racionalidade que rege as relações sociais e raciais, a conhecimentos avançados, indispensáveis para consolidação e concerto das nações como espaços democráticos e igualitários (BRASIL, 2004, p.6).

A problematização do currículo escolar, pelo enfrentamento do discurso hegemônico da normalidade do colonizador ocidental/europeu, dá visibilidade a outras lógicas e formas de pensar, contrapondo-se à ideia da existência de uma única lógica eurocêntrica e dominante que permeou o currículo no Brasil. Esse entendimento denuncia o currículo eurocentrado e hegemônico que não dá espaço para narrativas outras. Segundo Marques e Calderoni (2016, p.302), "Os saberes africanos e indígenas foram relegados a espaços estereotipados e subalternizados no currículo embranquecido que lhes impôs a condição de inferiores".

Argumentamos com Mignolo (2003) sobre a relação entre a colonialidade e a epistemologia, esta é um fio condutor para a universalização e subalternização de

como o trabalho, o conhecimento, a autoridade e as relações intersubjetivas se articulam entre si através do mercado capitalista mundial e da idéia de raça. (TORRES, 2007, p. 131). 
determinados saberes, pois nos permite contestar a hegemonia dos saberes ocidentais ainda que de forma silenciosa, segue impondo seus saberes nos currículos escolares.

Nesse estudo buscamos investigar de que forma as escolas públicas estaduais de Mato Grosso do Sul tem viabilizado a inserção das DCNERER, no currículo escolar das escolas públicas. Abordamos as questões epistêmicas na perspectiva da colonialidade do poder articulada por Quijano (2005). Para dar conta do objetivo, o texto está organizado da seguinte forma: a) no primeiro momento apresentamos as contribuições dos estudos pós-coloniais para contestar a lógica da modernidade/colonialidade; b) no segundo momento analisamos as marcas da colonialidade do poder no currículo escolar e, no terceiro momento apontamos as possibilidades trazidas pelas DCNERER para ressignificação do currículo. Finalizamos defendendo que há ainda um longo caminho para a efetivação de uma pedagogia intercultural e decolonial, contudo a subversão à logica da colonialidade do currículo tem sido tensionada como afirma Walsh (2009).

\section{MODERNIDADE/COLONIALIDADE: SUA LÓGICA E HEGEMONIA EPISTÊMICA}

Tratamos neste item da acepção epistêmica das chamadas teorias pós-coloniais, estas dão início a uma genealogia dos saberes ocidentais sobre os povos outros, assim, estabelecemos relações entre os contextos das relações coloniais e a colonialidade do poder, ser e saber, questionando a vinculação entre as ciências humanas e a hegemonia ocidental (SAID, 2003). Uma das principais inquietações desses estudos é organizar uma crítica ao mundo ocidental, repensar seu projeto epistêmico e contestar as teorias clássicas da modernização, levando-nos a admitir o caráter cultural, histórico, social dos saberes.

Propomos a problematizar os processos de significação e produção de saberes em países colonizados como o nosso, analisando como foram e são construídos ao longo da história de encontros entre culturais diferentes desde os tempos de colonização até a contemporaneidade. Neste sentido, Walsh (2009) corrobora ao nos afirmar que 
precisamos buscar um processo contínuo de descolonialização ${ }^{7}$; pois a suposta superioridade conferida ao saber do colonizador ocidental que ainda se sustenta pela colonialidade do ser saber e viver que subalterniza os outros saberes que não pertencem ao continente europeu.

Nessa perspectiva, cabe refletir sobre o que entendemos por colonização, colonialismo e colonialidade, que nos parece muito próximos, porém com entendimentos epistêmicos bastante distintos, fazendo necessário revisioná-los (BHABHA, 2003). Assim, Calderoni (2016) corrobora ao nos afirmar:

A articulação entre a colonização, colonialismo e colonialidade e a revisão desses processos e resistência abriram novas perspectivas para outras narrativas, diferentes das narrativas exclusivamente centradas e a partir dos discursos hegemônicos eurocentrados, criando assim, espaços de enunciações (BHABHA, 2003). E ao problematizar essas metanarrativas, segundo o autor, poderemos construir os entrelugares em que se abririam espaços de enunciações para conhecimentos outros (p.44).

Ao produzimos um processo revisionário da colonização, do colonialismo e da colonialidade ainda vigente e ao buscarmos uma atitude decolonial e intercultural, esta nos possibilita compreender o projeto epistêmico, colonial imposto a nação brasileira, passamos a compreender que "[...] o conhecimento do Outro e da terra era, pois, central aos objetivos de conquista dos poderes coloniais". Perceberemos que "O projeto colonial teve, desde início, uma importante dimensão educacional e pedagógica" afirma Silva (2007, p.128). Deste processo colonial derivou-se o sistema mundo moderno/universal, este sistema provocou construções discursivas e consequentemente relações devastadoras aos povos afrodescendentes e indígenas.

E, ao entender o projeto epistêmico colonial imposto a sociedade brasileira, percebemos também a imposição epistêmica curricular vigente. É interessante observar a hegemonia dos saberes no currículo, ou seja, não há como negar a hierarquia de saber imposta as questões raciais e étnicas.

\footnotetext{
${ }^{7}$ Descolonialidade, Decolonialidade são entendidos pelos autores pós-colonialistas como sinônimos. A orientação decolonial proposta por Walsh, busca questionar, rever as "[...] estruturas sociais, políticas e epistêmicas da colonialidade" (WALSH, 2009, p.24).
} 
Podemos afirmar que há uma relação de poder colonial vigente que ainda privilegia a epistemologia européia como nos aponta Dussel (2005) que a define como a "geopolítica do conhecimento". Essa epistemologia contribui para encobrir as hierarquias de poder raciais hegemônicas, deste modo vem sendo construída como uma instância de produção, controle e legitimação dos conhecimentos dos povos colonizadores, que no caso, com os saberes ocidentais, entendidos como universais.

Os conhecimentos dos povos colonizados, africanos e indígenas são negados, silenciados, neste entendimento tornam-se importantes aliados para hierarquização das culturas, visto que estes contribuem na introjeção de valores ocidentais, muitas vezes reforçados por meio de silenciamentos, subalternização de componentes culturais e da presença de estereótipos e preconceitos nos conteúdos, numa tentativa de neutralizar a diferença étnica existente (CALDERONI, 2016).

No Brasil, tivemos diversos povos, diversas etnias constituindo nossa nação, isto implicou numa relação de colonização, de dominação, onde os europeus por uma questão de poder se favoreceram, estabelecendo uma dominação epistêmica. Essa dominação derivou-se a diferença colonial que colocou às margens e subalternizou os saberes dos povos africanos e indígenas pelo pensamento colonial que apenas legitima uma forma de saber, a europeia, e marginaliza as outras formas de conhecimento, embora também identifiquemos os atravessamentos híbridos ${ }^{8}$.

Somos interculturais natos, entretanto, temos uma dificuldade enorme de abrimos a interculturalidade, de tratar das questões que envolvem os saberes que não fazem parte dos colocados como universais. Nos parece importante entender e nos aprofundar sobre a geopolítica dos saberes (DUSSEL, 2005), visto que a legitimação dos saberes se trata de uma construção histórica, cultural e social, ou seja, de projeto pedagógico social e cultural que tem no currículo escolar um instrumento pedagógico de colonização.

\footnotetext{
8 Temos entendimento de hibridismo desassociado das teorias da mestiçagem. Entendemos com Bhabha (2003) como conceitos com sentidos distintos. As teorias da mestiçagem são, inclusive, estranhadas pelo pós colonialistas. O hibridismo das identidades sociais num contexto (pós) colonial culturalmente tão rico e nuançado como nosso, não é apenas um instrumento de ruptura com a "unidade" cultural do colonizador, este representa-nos uma forma de resistência ao discurso do colonizador e uma possibilidade de construção identitária outra.
} 


\section{A COLONIALIDADE DO PODER E SUAS IMPLICAÇÕES PARA O}

\section{CURRÍCULO ESCOLAR}

Nos parece importante discutir a geopolítica do saber (DUSSEL, 2005), pois ela nos provoca a suscitar o debate sobre o que é considerado conhecimento no currículo escolar, como também, a compreende-lo como um texto político cultural.

Quijano (2003) contribui ao argumentar que a diferença colonial (povos com escrita alfabética, ou não) foi o primeiro pressuposto para a construção “[...] do imaginário do mundo colonial/moderno" (p. 23). Já no início do século XIX, o critério de avaliação, e consequentemente subalternização dos povos e saberes, "[...] não era mais a escrita, mas a história". Argumenta o autor, assim quem tinha a história, consequentemente detinha o poder. No próximo século foi "Max Weber que transformou o discurso dos missionários sobre essa lacuna em celebração de conquista, pelo Ocidente, do verdadeiro saber como valor universal” (QUIJANO, 2005, p. 23). E nesta construção histórica cultural que se encontra a colonialidade do poder vigente.

Sobre a suposta universalidade do conhecimento Quijano (2003) corrobora afirmando que:

Ao mesmo tempo em que se afirmava a dominação colonial, erigia-se um complexo cultural denominada racionalidade e estabelecia-se como o paradigma universal do conhecimento e das relações hierárquicas entre a 'humanidade racional' (Europa) e o resto do mundo (QUIJANO apud MIGNOLO 2003, p. 93, grifos do autor).

Santos (1999, p. 204-205), corrobora nesta discussão ao argumentar que "Não há conhecimento em geral, tal como não há ignorância em geral”, argumenta o autor, "O que ignoramos é sempre a ignorância de uma certa forma de conhecimento e, viceversa, o que conhecemos é sempre o conhecimento em relação a uma certa forma de ignorância”. Mignolo (2003), contribui ao afirmar que sempre falamos de uma localização particular nas relações de poder, ou seja os colonizadores tiveram o poder para definir os discursos sobre o colocado como outro. Tais entendimentos nos levam a reflexões e nos permitem formular as seguintes perguntas que me serão norteadoras: como trabalhar com um conhecimento e não outro? Porque alguns saberes entram nas práticas pedagógicas docentes e outros são marginalizados, subalternizados e ou mesmo ignorados? 
A herança colonial atuou em nosso processo civilizador e produziu a subalternização epistêmica ao hierarquizar e inferiorizar todos aqueles saberes que não se enquadravam no modelo eurocêntrico está também institucionalizou o colonizador e legitimando-o como superior.

A esse respeito, Nelson Maldonado-Torres (2007) explana como o colonialismo manteve-se presente em todo o processo de construção de uma sociedade brasileira moderna e democrática. Para este autor falar sobre o período colonial, remete a explanação de relação política e econômica, na qual e como consequência,

[...] a colonialidade se refere a um padrão de poder que emergiu como resultado do colonialismo moderno, mas em vez de estar limitado a uma relação formal de poder entre dois povos ou nações, se relaciona à forma como o trabalho, o conhecimento, a autoridade e as relações intersubjetivas se articulam entre si através do mercado capitalista mundial e da idéia de raça. Assim, apesar do colonialismo preceder a colonialidade, a colonialidade sobrevive ao colonialismo. Ela se mantém viva em textos didáticos, nos critérios para o bom trabalho acadêmico, na cultura, no sentido comum, na auto-imagem dos povos, nas aspirações dos sujeitos e em muitos outros aspectos de nossa experiência moderna. Neste sentido, respiramos a colonialidade na modernidade cotidianamente (MALDONADO-TORRES, 2007, p. 131).

Dessa forma, é válido dizer que a colonialidade, como resultado de uma imposição de poder e dominação colonial (colonialismo), chega às estruturas idearias de um povo e penetra na concepção individual de seus sujeitos, e consequentemente entendem por sociedade, de tal forma que mesmo após a desvinculação desse domínio, as amarras ainda são vividas.

A subjetividade, neste ponto, serve para manter a pseudo-aceitação de todo indivíduo como membro de uma sociedade, ou nas palavras de Walter Mignolo (2005), a invenção de um indivíduo. Para o autor as ciências humanas, incluindo a história, legitimada pelo Estado, cumpriram um papel crucial nesse processo de construção de um "outro", situando-o aquém da definição de civilizado, e o tornando referência de atraso em contraposição ao moderno, sofisticado e civilizado, no nosso caso, os europeus colonizadores. Fanon (2003) vai além, defende que o colonizador, foi tão à fundo no processo de colonização que estabeleceu uma compreensão maniqueísta de sociedade, pois não bastou, 
limitar fisicamente o colonizado, com suas polícias e seus exércitos, o espaço do colonizado. Assim, para ilustrar o caráter totalitário da exploração colonial, o colonizador faz do colonizado uma quintessência do mal. A sociedade colonizada não somente se define como uma sociedade sem valores. Não basta ao colono afirmar que os valores desertaram, ou melhor jamais habitaram, o mundo colonizado. O indígena é declarado impermeável à ética, aos valores. É, e nos atrevemos a dizer, o inimigo dos valores. Neste sentido, ele é um mal absoluto. Elemento corrosivo de tudo o que o cerca, elemento deformador, capaz de desfigurar tudo que se refere à estética ou à moral, depositário de forças maléficas. (FANON, 2003, p. 35-36).

Ao refletirmos com os autores supracitados, argumentamos sobre a importância das propostas curriculares interculturais e decoloniais porque estas trabalham na perspectiva de diversidade e diferença cultural e possibilitam a contestação e a descolonização do currículo escolar. A introdução de práticas interculturais e decoloniais possibilitam a revisão da política de currículo, e esse processo cria uma atitude de descolonização do próprio currículo.

Trata-se de questões que não são fáceis de serem repensadas, não é tarefa fácil o exercício epistêmico de "[...] desaprender o aprendido para voltar a aprender", (JUAN GARCIA, apud WALSH, 2009, p.24), tomando como exercício epistemológico e ontológico, na perspectiva de decolonialidade (WALSH, 2009).

O currículo escolar é um conhecimento selecionado, nele permanece a manutenção das hierarquias raciais e étnicas do período da colonização brasileira, conforme apresentada na perspectiva da colonialidade do poder, ser e saber (QUIJANO, 2003). Há uma dificuldade na construção curricular e nas práticas pedagógicas das escolas devido o grau de interferência do contexto de nossa colonização que define os saberes de uma sociedade. Assim, busca-se manter o pensamento pedagógico e curricular que se constituiu pelas instituições gestoras que seguimos reproduzindo até hoje.

Ao que parece, evocar o discurso da suposta universalidade do saber tem sido uma estratégia recorrente ao construir os currículos escolares e, como tal, constitui aquilo que se denomina de hegemonia eurocêntrica. 
A IMPLEMENTAÇÃO DAS DIRETRIZES CURRICULARES DIRETRIZES

CURRICULARES NACIONAIS PARA EDUCAÇÃO DAS RELAÇÕES ÉTNICO-RACIAIS NAS ESCOLAS DE MATO GROSSO DO SUL (MS).

A implementação das DCNERER (BRASIL, 2004) representou um avanço significativo para o currículo escolar, pois possibilita tensionamentos no currículo colonizado no viés das práticas monoculturais. Sua efetiva orientação pode promover a ressignificação da história do povo negro e indígena, a cultura, o conhecimento, o reconhecimento da diversidade étnico-racial presente na sociedade brasileira que até o presente segue negada no currrículo. Desafia educadores, gestores e alunos a discutir o que antes era silenciado ou apresentado de forma subalternizada e inferiorizada.

Reconhecer e propor uma reconstrução dessa sociedade que ainda é bastante desigual é responsabilidade de todos os brasileiros. A tarefa é árdua e passa necessariamente pela educação, como instituição que deve objetivar a arquitetura de um convívio humano com a diferença (e com os diferentes), por meio de um exercício cotidiano sadio e natural, construindo relações que se pautem no respeito e nas igualdades sociais e de oportunidades, características naturais da democracia.

Os documentos norteadores das políticas curriculares no Brasil refletiram a negação da diferença presente na sociedade, por meio da colonialidade do ser, saber e viver que inviabilizaram outras lógicas. Com as mudanças trazidas pela proposta de inserir no currículo escolar a diferença negra e indígena, a escola teve a possibilidade de questionar a lógica hegemônica de uma cultura comum, de base ocidental e eurocêntrica.

Silva (2012) afirma que a partir das pesquisas já realizadas sobre a temática, é possível identificar que "a estratégia ideológica do silêncio é particularmente atuante no estabelecimento do branco [...] como norma e como superior hierarquicamente" (p.117), reflexo evidente do colonialismo. Ainda nesse sentido, é o silêncio que mantém o discurso, na escola, que tenta "construir a igualdade entre os alunos a partir de um ideal de democracia racial" (GONÇALVES, 1987), ocultando os processos de discriminação.

Nessa perspectiva, apresentamos nessa seção, os resultados da pesquisa realizada em escolas públicas do estado de Mato Grosso do Sul sobre a implementação da História e Cultura Afro-brasileira e Indígena no currículo escolar. O procedimento 
metodológico consistiu em visitas as escolas, análise, dos Projetos pedagógicos, análise das imagens e conteúdos dos livros didáticos e paradidáticos adotados. Também utilizamos a aplicação de um questionário semiestruturado (on line) aos professores, diretores de escolas e coordenadores pedagógicos de 169 escolas distribuídas em 79 municípios de Mato Grosso do Sul (MS).

Neste artigo analisaremos algumas percepções dos professores e coordenadores pedagógicos entrevistados sobre os desafios para a implementação das DCNERER (2004) e elegemos as questões respondidas pelos participantes que objetivaram identificar sobre o conhecimento das alterações trazidas pelas legislações. 1) $O$ que você sabe sobre a Lei $n^{o}$. 10.639/03 e $n^{o} 11.645 / 08$ ? 2) Você considera a temática da diversidade étnico-racial necessária no currículo escolar? 3) Quais as dificuldades para implementação da Lei $n^{\circ} 10.639 / 03$ e $n^{o} 11.645 / 08$ nas escolas de um modo em geral? 4) Você desenvolve atividades que atendam às DCNERER?

Sobre o conhecimento das referidas legislações, um total de $57 \%$ dos professores ação respondeu que conhecem as leis. Outros $34 \%$ de afirmaram conhecer parcialmente. Isso significa que $91 \%$ dos professores já tiveram contato, de alguma forma, com os pareces ou termos norteadores envolvendo a temática étnica e racial no país, seja no espaço escolar ou fora dele.

No que se refere à importância de inserção no currículo, tivemos um total de $4 \%$ de professores que não consideram necessário trabalhar com a temática da diversidade étnico-racial. Embora seja um percentual baixo, merece atenção, principalmente na formação das crianças da educação básica. A esse respeito, Silva (2007, p.201) argumenta que:

O desconhecimento das experiências de ser, viver, pensar e realizar de índios, de descendentes de africanos, de europeus, de asiáticos, faz com que ensinemos como se vivêssemos numa sociedade monocultural. Isto nos torna incapazes de corrigir a ilusão da democracia racial, de vencer determinações de sistema mundo centrado em cosmovisão representativa de uma única raiz étnico-racial. Impede-nos de ter acesso a conhecimentos de diferentes origens étnico-raciais, e ficamos ensinando um elenco de conteúdos tido como o mais perfeito e completo que a humanidade já teria produzido. Tornamo-nos incapazes de perceber as vozes e imagens ausentes dos currículos escolares: empobrecidos, mulheres, afrodescendentes, africanos, indígenas, idosos, homossexuais, 
deficientes, entre outros. Para superar a tudo isto, precisamos ultrapassar estereótipos, extinguir preconceitos, e como disse Senghor, em um de seus poemas, proceder a uma "desintoxicação semântica", isto é, redefinir termos e conceitos, por exemplo, no nosso caso do campo educacional, a começar por educação, aprender, ensinar, saber, educar, educar-se.

As possibilidades de ressignificação do currículo escolar, numa perspectiva de educar para as relações étnico-raciais desafiam o fazer pedagógico, para tanto, a atuação do professor é, sem dúvida, um dos fatores mais significativos nesse processo, daí a necessidade de formação continuada para que os professores possam compreender que a construção de uma educação antirracista, intercultural e decolonial depende muito do modo como os conhecimentos foram aprendidos e são ensinados.

A seguir apresentamos, no quadro 1, as respostas dos entrevistados, sobre as dificuldades para implementação da Lei $n^{\circ} 10.639 / 2003$ e $n^{\circ} 11.645 / 2008$ nas escolas de um modo em geral.

Quadro 1 - Dificuldades para a implementação das Leis

"Falta de subsídios específicos para abordar o tema, tais como: capacitação específica para os professores aprimorarem suas ideias, materiais didáticos e paradidáticos. Além disso podemos citar a questão do tempo cronológico de atividades que impedem um estudo mais aprofundado". (Professor de Matemática).

"A forma que o conteúdo aparece nos livros didáticos e no material enviado às escolas. Pois poderiam ser mais dinâmicos e pontuarem alguns aspectos ainda vivos destas culturas em nossa sociedade". (Professora do $5^{\mathrm{a}}$. Ano).

"São poucas disciplinas que possuem embasamento teórico para trabalhar o tema, as demais áreas não possuem embasamento teórico em suas formações". (Professora de História do $7^{\circ}$. Ano).

"Tempo, disponibilidade, afinal lidamos com vários fatores inerentes a educação: inclusão, bullying, violência, gravidez na adolescência... é difícil atender a todos e tantos". (Diretora Escolar).

"Falta de conscientização por parte da população, a influência de outros valores religiosos". (Professora de Artes).

"A influência dos valores religiosos e a predominância do valor cultural, capitalista, dos brancos". (Professora de Língua Portuguesa).

"A falta de formação bem como de material adequado tem dificultado a implementação das leis. A escola até tem recebido alguns livros do programa FNDE, porém, esse material não tem chegado até os professores e quando chega não desperta o interesse dos mesmos por serem mais teóricos e não trazerem sugestões mais objetivas de como se trabalhar esses assuntos em sala de aula". (Coordenadora Pedagógica).

"Essas leis tentam combater o racismo, mas esquecemos que quanto mais falarmos do 
racismo, mais tempo ele vai durar, acho que essas leis na verdade tem o efeito oposto do que diz sua proposta. Se vamos aprender sobre a história africana, devemos aprender sobra a japonesa, a italiana, e a de outras culturas que também tiveram suas contribuições para o Brasil. Essa lei passa a ideia de que existem apenas duas raças no mundo, negro e branco, quando isso não é verdade". (Professora de Educação Física).

Fonte: Sistematizado pelas autoras

Embora os depoimentos demonstrem que a educação para as relações étnicoraciais exige mais conhecimento das legislações supracitadas e formação continuada, identificamos, de certo modo, um movimento afirmativo, pelo fato de estarem presentes nas falas dos investigados indícios de que as leis tensionaram o fazer pedagógico. Ou seja, a diferença, mesmo que de forma tímida e as vezes equivocada que está presente no processo educativo exige reflexões alheias à pedagogia homogeneizadora e eurocêntrica, indicando um começo para a construção de uma pedagogia intercultural e decolonial.

As falas da coordenadora pedagógica e da diretora escolar no quadto 1, refletem de certa forma, a passividade da escola diante dessa realidade que não contribuem para garantir a ressignificação do currículo, todavia identificamos atuações individuais e coletivas de professores de diferentes áreas que estão desenvolvendo em suas disciplinas alguma atividade que possibilitam a descolonização curricular e a ressignificação do ensino de história e cultura afro-brasileira e indígena, nas respostas à questão: Você desenvolve atividades que atendam às DCNERER?

No quadro 2, a seguir mostramos as falas de alguns professores sobre a implementação das Diretrizes Curriculares Nacionais para a Educação das relações étnico-raciais nas escolas de MS.

Quadro 2 - A implementação das DCNERER nas escolas

"Eu busco atender às diretrizes e inserir dentro do conteúdo as discussões por meio de leituras, debates sobre a História da África e o legado deixado em nossa cultura". (Professor de História).

"Trabalhamos durante o mês de novembro várias atividades que abordam essa temática como seminários, filmes e apresentações que são apresentadas no dia 20 de novembro". (Professora de Ciências). 
"A partir de pesquisar, oficinas e projeto que envolve toda a escola" (Professora de História).

"Na nossa escola trabalhamos para incentivando a valorização da cultura indígena, que é a nossa realidade". (Professora de História).

"Realizo o projeto ancestralidades e convido membros do Movimento Negro para palestras". (Professora de Língua Portuguesa).

"Estudo a arte africana e confeccionamos máscaras e as pinturas de Debret" (Professora de Artes).

"A partir da liberdade dada aos docentes, no que se refere à execução dos planejamentos, de acordo com o "Referencial Curricular" explicitado". ( Professora do $2^{\circ}$.ano).

"Temos um projeto chamado festa das nações onde são trabalhados a cultura, a comida, os hábitos que foram trazidos para nos pelos negros e indígenas". (Professora do $3^{\circ}$ ano). (Grifos nossos).

"Somente quando se comemora o 20 de novembro, no contraturno por ser escola integral conseguimos fazer atividades alusivas aos temas". (Coordenadora pedagógica).

"Ministrando os conteúdos essenciais, atividades, apresentações e discussões sobre o assunto, pesquisas e buscas de imagens e vídeos, recursos tecnológicos". (Professor de Língua Inglesa).

"Quando recebemos algum material do MEC ou da SED". (Professora $4^{\circ}$ ano).

"Com músicas de rappers que falam de racismo e desigualdades sociais (Professora Língua Portuguesa).

Fonte: Sistematizado pelas autoras

A leitura dos dizeres dos entrevistados nos permite perceber que, de alguma forma, os professores desenvolvem atividades referentes à inserção da história e cultura africana, afro-brasileira e indígena em suas disciplinas. Contudo, a cultura e história dos povos indígenas é pouco citada pelos professores. Inferimos que as alterações trazidas pela Lei n. 10.639/2003 foi mais efetiva, devido ao longo processo de tensionamento do Movimento Negro e as denúncias sobre o monoculturalismo e o etnocentrismo presente no currículo escolar.

Enquanto a Lei $\mathrm{n}^{\mathrm{o}}$ 10.639/2003 representou uma conquista significativa da população negra, resultante de um ato político e jurídico, a alteração trazida pela Lei $\mathrm{n}^{\circ}$ 11.645/2008 que insere na LDBEN/96 o ensino da história e cultura indígena, foi um ato de legislativo que não teve outros desdobramentos no Conselho Nacional de Educação, no tocante à implementação de Diretrizes específicas. Mesmo nas escolas não-indígenas de MS existem crianças de diferentes etnias, as comemorações e atividades referentes à cultura afro-brasileiro é majoritária. Os subsídios didáticos que 
existem nas escolas adquiridos pelos gestores ou enviados pelo MEC também possuem essa mesma representatividade e dissonância.

As legislações que promoveram uma ruptura com o currículo monocultural estão em vigor há 15 (quinze anos) anos os estudos sobre essas legislações permanecem, com o objetivo de traçar um panorama sobre o alcance e a efetividade ou os mecanismos de resistência.

Sob essa ótica, concordamos com Stephen J. em entrevista

Quero rejeitar completamente a ideia de que as políticas são implementadas. Eu não acredito que políticas sejam implementadas, pois isso sugere um processo linear pelo qual elas se movimentam em direção à prática de maneira direta. Este é um uso descuidado e impensado do verbo. O processo de traduzir políticas em práticas é extremamente complexo; é uma alternação entre modalidades. A modalidade primária é textual, pois as políticas são escritas, enquanto que a prática é ação, inclui o fazer coisas. Assim, a pessoa que põe em prática as políticas tem que converter/transformar essas duas modalidades, entre a modalidade da palavra escrita e a da ação, e isto é algo difícil e desafiador de se fazer (apud MAINARDES; MARCONDES, 2009, p. 305).

A análise de política curricular na concepção de Ball remete a uma construção de abordagem cíclica, permeada pela heterogeneidade de discursos e diversidade de sujeitos e grupos sociais que delas participam, assim, as políticas de currículo também podem ser vistas, como resultado de um contínuo ciclo de políticas. (BALL, 2009; 2011).

Nesse contexto, é importante a compreensão de que as ações da escola não estão totalmente engessadas pelo estado e que os seus atores simplesmente cumprem de forma verticalizada as determinações. No caso das DCNERER (2004) o movimento de resistência e de subversão à lógica colonial e monocultural do currículo escolar se deu anterior à ação do Estado e, no fazer pedagógico, mesmo com as diretrizes oficiais, ainda há movimento de resistência de alguns professores.

Considero importante superar tanto modelos que entendem as relações do Estado sobre a prática das escolas como verticalizadas, reservando às escolas o papel subordinado de implementação e ao Estado, uma ação onipotente, quanto análises que desconectam as práticas das relações com processos sociais e político-econômicos mais amplos, mediados pelo Estado. Do ponto de vista teórico, defendo que tal ampliação pode ser construída por intermédio da 
incorporação das análises contemporâneas sobre a cultura à interpretação das relações entre Estado e políticas de currículo. (LOPES, 2006, p.35).

Desse modo, a implementação das DCNERER ( 2004) não representa o seu completo enraizamento ou alterações na prática docente ou na formação inicial dos cursos de licenciatura, bem como nos processos de formação inicial e continuada de professores, pois os deslocamentos epistêmicos trazidos pelas Leis enfrentam, conforme ressalta Gomes ( 2009, p.42), “ [...] as práticas e o imaginário racial presentes na estrutura e no funcionamento da educação brasileira, tais como o mito da democracia racial, o racismo ambíguo, a ideologia do branqueamento e a naturalização das desigualdades raciais".

Nesse depoimento "Trabalhamos durante o mês de novembro várias atividades que abordam essa temática como seminários, filmes e apresentações que são apresentadas no dia 20 de novembro". (Professora de Ciências), identificamos que a Lei 10.639/2003 ao inserir o dia 20 de novembro - Dia da Consciência Negra atendeu também uma reivindicação histórica do Movimento Negro no sentido de homenagear o Líder negro Zumbi dos Palmares e deslocar a ênfase equivocada dada nos currículos escolares ao dia "13 de maio - Abolição da Escravidão", justamente por questionar que essa data não representou por si só a libertação, considerando que:

Os poderosos capitularam, perderam, mas não se entregaram. A lei deveria ter sido votada com um amplo apoio, indenização e reintegração dos escravizados à sociedade brasileira. Entretanto, os poderosos omitiam a discussão do direito da população que tinha sido escravizada. Fizeram um esforço e conseguiram que a sociedade nunca discutisse o escravismo a luz dos valores éticos e morais. Fizeram uso dos meios de propaganda para transformar pessoas criminosas em generosas. Generosas por terem "dado" a liberdade aos negros. Isto foi e ainda é uma manipulação de informação histórica (CUNHA JÚNIOR, 2017)9 .

As escolas realizam diferentes atividades no mês de novembro, mas é preciso uma avaliação crítica por parte dos professores se as atividades não são folclorizadas ou

\footnotetext{
${ }^{9}$ Disponível em http://www.historianet.com.br/conteudo/default.aspx?codigo=508. Acesso em $21 \mathrm{de}$ jan.de 2019).
} 
reforçam os estereótipos sobre os negros, no que tange à alimentação e a dança. Isso requer formação continuada por parte dos sistemas de ensino e, de acordo com a pesquisa realizada, os professores consideram importante a formação continuada, mas a maioria nunca participou de formação específica sobre a temática e a lacuna deixada na formação inicial dificulta a prática pedagógica intercultural e decolonial.

De um modo em geral, a pesquisa de campo mostrou que: a) As legislações promoveram desacomodações e inquietações ao currículo monocultural; b) As DCNERER possibilitaram um deslocamento epistêmico no conhecimento legitimado no currículo; c) Existem nas escolas projetos coletivos e individuais que trabalham na perspectiva da Educação das Relações Étnico-raciais, identificamos também resistência de alguns entrevistados que não consideram necessário conhecer as legislações, em suas falas até mesmo banalizam e ignoram as conquistas históricas e a luta do povo negro; d) A resistência ou o silenciamento sobre a História e Cultura Indígena ainda prevalecem, ou seja as práticas curriculares das escolas investigadas continuam comemorando o Dia do Índio, sem realizar nenhuma reflexão sobre os sérios problemas sociais e de conflitos territoriais que a população indígena enfrentam no Estado; e) O mito da democracia racial está presente em muitos depoimentos e a proposta das diretrizes são diluídas no discursos da "diversidade" e da "igualdade" , não problematizando a diferença, reforçando, assim, o imaginário social e a pedagogia do "silenciamento"; f) A Secretaria de Educação ofertou um curso de especialização lato sensu com adesão voluntária sobre Currículo, diversidade, gênero, raça e etnia que não atende as demandas de docentes de todo o Estado de MS.

Sobre as falas dos entrevistados percebemos a necessidade de aprofundarmos nossas pesquisas observando as práticas curriculares no âmbito do cotidiano escolar, pois percebemos que no campo do currículo as questões referentes à assunção da consolidação das legislações supracitadas precisam ser verificadas se estão sendo cumpridas nas práxis. Entendemos com Sacristán (2000, p. 15) que "o currículo é uma práxis antes que um objeto estático emanado de um modelo coerente de pensar a educação ou as aprendizagens necessárias das crianças e dos jovens".

\section{ALGUMAS REFLEXÕES PARA TERMINAR ESTE AGORA}


Objetivamos com este texto apresentar uma analise orientada pelas lentes dos autores pós colonialistas sobre o currículo escolar, problematizando as questões epistêmicas que envolvem a aplicação das DCNERER no cotidiano das escolas públicas de educação básica, por entender que há muito que pensar sobre que conhecimento são legitimados na escola. Trata-se de questões importantes na medida em que nos apresenta a compreensão dos diversos mundos em que habitamos e, especificamente, seus saberes e seu viver.

Permanecem várias questões e inquietações sobre como contestar a diversidade e a diferença cultural contida nos currículos escolares, visto que este se encontra sustentado numa postura relativista, universalista no que se refere ao que se conta como conhecimento. Como nos afirma Amamtea, et all, (2006, p.39), "[...] das finalidades da seleção cultural e da distribuição social do conhecimento no contexto do sistema escolar, sempre atravessadas por determinações históricas e políticas".

Neste caminho investigativo procuramos enfatizar que há uma desarticulação entre o que versa as leis $n^{\circ} 10639 / 2003$ e $n^{\circ} 11645 / 2008$, as DCNERER e as políticas curriculares vigentes nas escolas públicas, visto que na maioria das unidades investigadas, as questões de raça, etnia, gênero, sexualidade e identidade são tratadas como adereços e de forma estanque. Seria o pensamento colonial que estaria impedindo e instituindo este descompasso entre o sujeito pós-colonial que hoje temos como estudantes em sala de aula (constituidores de identidade, sexualidade, raça, etnia) e as práticas pedagógicas que ainda seguem colonizando e instituindo um lugar subalterno a determinados sujeitos culturais.

Percebemos que a colonialidade do poder não é experimentada de forma homogênea por todos, por isso, as "marcas de poder" (QUIJANO, 2003), continuam sendo as "marcas diferenciales de etnicidade e raza" (WALSH, 2006, p. 53). Já a construção do racismo negou e segue negando as diferenças culturais através da colonialidade do ser, saber e viver.

Algumas inquietações mobilizam nosso pensar para este agora, outras tantas ficam para continuarmos pensando: Quais as consequências da utilização de um currículo monocultural na implementação de políticas públicas? Será que não 
estaríamos reforçando e, portanto, oficializando as desigualdades a que tanto temos resistido em identificar como sendo de natureza racial? Negando a legitimação dos saberes dos povos colonizados não estaríamos reforçando as desigualdades sociais e culturais a que tanto temos medo de discutir?

Por fim, cabe destacar que educar para as relações étnico-raciais representa reconhecer a longa trajetória de enfrentamento e luta dos movimentos negros e indígenas por direito à visibilidade, ao reconhecimento e à ressignificação e desconstrução da herança colonial. Sabemos que há ainda muitas barreiras e disputas no campo do currículo para a efetivação de uma pedagogia intercultural e decolonial, contudo a pesquisa revela um movimento afirmativo, a partir das DCNERER que leva a subversão à logica da colonialidade contida no currículo escolar.

\section{REFERÊNCIAS BIBLIOGRÁFICAS}

BHABHA, Homi K. O local da cultura. Belo Horizonte: Ed. UFMG, 2003.

BRASIL, Constituição da República Federativa do Brasil. Brasília: Senado Federal, 1988. Disponível em: http://www.planalto.gov.br/ccivil_03/Constituicao/Constituicao.htm. Acesso em 15 de março de 2018.

BRASIL. Conselho Nacional de Educação/Conselho Pleno. Parecer 3/2004: Institui Diretrizes Curriculares Nacionais para a Educação das Relações étnico-raciais e para o ensino de História e Cultura Afro-brasileira e Africana. Diário Oficial da União, Brasília, 22 de maio de 2004, seção 1, p.11.

Lei de Diretrizes e Bases da Educação. Lei no 9.394, de 20 de dezembro 1996. Estabelece as diretrizes e bases da educação nacional. Diário Oficial [da] República Federativa do Brasil. Brasília,_DF, 20 dez.1996. Disponível em: <http://www.planalto.gov.br/ccivil_03/LEIS/19394.htm>. Acesso em: 22 jul. 2020 .

Lei $n^{\circ}$. 10.639, de 9 de janeiro de 2003. Altera a Lei n. 9.394, de 20 de dezembro de 1996, que estabelece as diretrizes e bases da educação nacional, para incluir no currículo oficial da Rede de Ensino a obrigatoriedade da temática "História e Cultura Afro-Brasileira", e dá outras providências. Diário Oficial da União, $1^{\circ}$ jan. 2003. Disponível em: <www.mp.rs.gov.br/infancia/legislacao/id221.htm>. Acesso em: 13 Abr. 2020.

Lei n. 11.645 de 10 de março de 2008. Altera a Lei n. 9.394, de 20 de dezembro de 1996, que estabelece as diretrizes e bases da educação nacional, para incluir no currículo oficial da Rede de Ensino a obrigatoriedade da temática "História e Cultura Afro-Brasileirae indígena. Disponível em: <http://www.planalto.gov.br/ccivil_03/_Ato2007-2010/2008/Lei/L11645.htm>. Acesso em: 20 Abr. 2020 .

Conselho Nacional de Educação/Conselho Pleno.Resolução n. 1 de 17 de junho de 2004. Institui Diretrizes Curriculares Nacionais para a Educação das Relações étnico-raciais e para o ensino de História e Cultura Afro-brasileira e Africana. Diário Oficial da União, 22 de junho de 2004, seção 1, p.11.

CALDERONI, Valéria Aparecida Mendonça de Oliveira - Professores indígenas e educação superior: traduções e negociações na Escola Indígena Ñandejara da Aldeia Te'ýikue, Caarapó/MS. Tese (doutorado em educação) - Universidade Católica Dom Bosco, Campo Grande, 2015. 
CASTRO-GÓMEZ, Santiago. La poscolonialidad explicada a los ninõs. Bogotá: Editorial Universidad Javeriana, 2005.

DUSSEL, Henrique. Europa, Modernidade e eurocentrismo. In: LANDER, Edgardo (Orgs). A colonialidade do saber: eurocentrismo e ciências sociais. Perspectivas latino -americanas. Buenos Aires: Clacso, 2005, p.55-70.

FANON, Frantz. Los condenados de la tierra. México: Fondo de Cultura Económica, 2003.

FERNANDES, Luiz F.de O. CANDAU, Vera, M.F. Pedagogia decolonial e educação antirracista e intercultural no Brasil. Educação em Revista | Belo Horizonte | v.26 | n.01 | p.15-40 | abr. 2010

GOMES, Nilma Lino. Limites e possibilidades da implementação da Lei $n^{\circ} 10.639 / 03$ no contexto das políticas públicas em educação. In: HERINGER, Rosana; PAULA, Marilene de. (Org.). Caminhos convergentes: estado e sociedade na superação das desigualdades raciais no Brasil. Rio de Janeiro: Henrich Boll Stiftung; Action Aid, 2009.

GONÇALVES E SILVA, Petronilha Beatriz. Aprender, ensinar e relações étnico-raciais no Brasil étnico-raciais no Brasil. Educação. Porto Alegre/RS, ano XXX, n. 3 (63), p. 489-506, set./dez. 2007.

CUNHA JÚNIOR. Henrique. A Abolição da Escravidão 13 de Maio: A Revolução Social Brasileira. Disponível em http://www.historianet.com.br/conteudo/default.aspx?codigo=508. Acesso em 21 de jan.de 2017).

LOPES, Alice Casimiro. Discursos nas políticas de currículo. Currículo sem Fronteiras, v.6, n.2, pp.3352, Jul/Dez 2006.

MANCINI, Ana Paula Gomes; TROQUEZ, Marta Coelho Castro. Desconstruindo estereótipos: apontamentos em prol de uma prática educativa comprometida eticamente com a temática indígena. Tellus, ano 9, n.16, p. 181-206, jan./jun. 2009. Campo Grande - MS.

MARQUES, Eugenia Portela de Siqueira; FILHO, Miguel Gomes. Educação, diversidades e inclusão: os

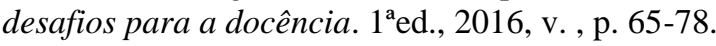

MARQUES, Eugênia Portela Siqueira; CALDERONI, Valeria Aparecida Mendonça de Oliveira. Os deslocamentos epistemológicos trazidos pelas leis 10.639/2003 e 11.645/2008: possibilidades de subversão à colonialidade do currículo escolar. OPSIS, Catalão - GO, v. 16, n. 2, p. 299-315, jul./dez. 2016.

MATO, Daniel. Diferenças Culturais, Interculturalidade e Inclusão na Produção de Conhecimentos e Práticas Socioeducativas. CANDAU, Vera Maria (org.). Educação Intercultural na América Latina: entre concepções, tensões e propostas. Rio de Janeiro: 7 Letras, 2009.

MIGNOLO, Walter. Histórias Locais - Projetos Globais Colonialidade, saberes subalternos e pensamento liminar. Walter Mignolo; Tradução de Solange Ribeiro de Oliveira. Belo Horizonte: Editora UFMG, 2003. $505 \mathrm{p}$.

PARAÍSO, Marlucy Alves. Metodologias de pesquisas pós-críticas em educação e currículo: trajetórias, pressupostos, procedimentos e estratégias analíticas. In: MEYER, Dagmar Estermann, PARAÍSO, Marlucy. Pesquisas pós-críticas em educação no Brasil: esboço de um mapa. Cadernos de Pesquisa, v.34, n 122, p. 46-56, 2012.

QUIJANO, Anibal. Coloinalidad del poder, eurocentrismo y América Latina. In: LANDER, Edgardo. Org. La colonialidad del saber eurocentrismo y ciências sociales. Perspectivas Latinoamericanas. Buenos Aires: Clacso, 2005.p.201-246._2003. 
RUSSO, Kelly; PALADINO, Mariana. A lei n. 11.645 e a visão dos professores do Rio de Janeiro sobre a temática indígena na escola. Revista Brasileira de Educação v. 21 n. 67 out.-dez. 2016.

SACRISTÁN, J. G. O Currículo: Uma Reflexão sobre a Prática. Trad. Ernani F. da F. Rosa. $3^{a}$ ed. Porto alegre: ArtMed, 2000.

SAID, Edward. Reflexões sobre o exílio e outros ensaios. São Paulo: Companhia das Letras, 2003.

SANTOS, Boaventura. S. Porque é tão difícil construir uma teoria crítica? .In: Revista de Ciências Sociais, Coimbra, nº 54, p.197-215, junho. 1999.

SILVA, Tomaz Tadeu da. (Org.) Documentos de identidade: uma introdução às teorias do currículo. 2. ed., 11 ${ }^{a}$ REIMP.- Belo Horizonte: Autêntica, 2007.

MAINARDES, Jefferson; MARCONDES, Maria Inês. Entrevista com Stephen J. Ball: um diálogo sobre justiça social, pesquisa e política educacional. Educ. Soc., Campinas, v. 30, n. 106, p. 303-318, Apr. 2009. Available from <http://www.scielo.br/scielo.php?script=sci_arttext\&pid=S010173302009000100015\&lng=en\&nrm=iso>. access on 17 Abr. 2020. http://dx.doi.org/10.1590/S0101$\underline{73302009000100015 .}$

MALDONADO-TORRES, N. Sobre la colonialidad del ser: contribuciones al desarrollo de um concepto. In: CASTRO-GÓMEZ, S. y GROSFOGUEL, R. (Orgs.) El giro decolonial. Reflexiones para una diversidad epistémica más allá del capitalismo global. Bogotá: Universidad JaverianaInstituto Pensar, Universidad Central-IESCO, Siglo del Hombre Editores, 2007. p. 127-167.

WALSH, Catherine. Interculturalidad y colonialidad del poder: un pensamiento y posicionamiento otro desde la 'diferencia colonial. In: WALSH, Catherine. et al. Interculturalidad, descolonización del estado e del conocimiento. Buenos Aires: Signo, 2006. p. 21-70.

Interculturalidade Crítica e Pedagogia Decolonial: in-surgir, re-existir e reviver. CANDAU, Vera Maria (org.). Educação Intercultural na América Latina: entre concepções, tensões e propostas. Rio de Janeiro: 7 Letras, 2009, p.12- 42.

Recebido 30/03/2020

Aprovado em 30/04/2020 